\title{
Information Retrieval on Turkish Texts
}

\author{
Fazli Can, Seyit Kocberber, Erman Balcik, Cihan Kaynak, H. Cagdas Ocalan and Onur M. Vursavas \\ Bilkent Information Retrieval Group, Computer Engineering Department, Bilkent University, Bilkent, \\ Ankara 06800, Turkey. E-mail: \{canf, hocalan\}@cs.bilkent.edu.tr, seyit@bilkent.edu.tr, \\ erman.balcik@siemens.com,kaynakc@muohio.edu,onur.vursavas@hp.com
}

\begin{abstract}
In this study, we investigate information retrieval (IR) on Turkish texts using a large-scale test collection that contains 408,305 documents and 72 ad hoc queries. We examine the effects of several stemming options and query-document matching functions on retrieval performance. We show that a simple word truncation approach, a word truncation approach that uses language-dependent corpus statistics, and an elaborate lemmatizer-based stemmer provide similar retrieval effectiveness in Turkish IR. We investigate the effects of a range of search conditions on the retrieval performance; these include scalability issues, query and document length effects, and the use of stopword list in indexing.
\end{abstract}

\section{Introduction}

With Internet technology, the increase in the size of online text information, and globalization, information retrieval (IR) has gained more importance, especially in commonly used languages. Turkey is the 22nd-largest economy (Anderson \& Cavanagh, 2006), and the Turkish language is among the most commonly used 20 languages in the world (Grimes \& Grimes, 1996); however, Turkish IR is a field that has not gained much interest. This is partly due to the nonexistence of standard IR test collections in Turkish. In this study, we aim to provide such a collection. Furthermore, working with an agglutinative language such as Turkish instead of a member of the Indo-European family is a real and important issue since there are much work to be done in such languages within the context of IR research and develoment. The commercial Web search engines such as Turkish-specific ones and Google provide access for Turkish text, but their search techniques are trade secrets. On the other hand, many applications, from personal information management to national security, need effective methods in various languages. We provide the first thorough investigation of information retrieval with a large-scale Turkish test collection (A

Received December 23, 2006; revised August 3, 2007; accepted August 3, 2007

(C) 2007 Wiley Periodicals, Inc. • Published online 4 December 2007 in Wiley InterScience (www.interscience.wiley.com). DOI: 10.1002/asi.20750 preliminary version of this study can be seen in Can et al., 2006.) In this study, we examine the effects of several stemming algorithms and query-matching functions, and various system parameters on retrieval effectiveness.

The first component of IR research on effectiveness is the test collection. In IR, standard test collections follow the Cyril Cleverdon's Cranfield tests tradition of laboratory experiments and involve three components: a set of documents, a set of user information requests or topics, and a set of relevance judgments made by human assessors for each topic (Sparck Jones, 1981) (The internal representation of these information needs is referred to as queries; however, in the article, we refer to the the written forms of user information needs as queries. This is to prevent confusion since, as will be seen later, in the written form of the user information requests we have three fields, and one of them is called topic.) Test collections facilitate reproducibility of results and meaningful effectiveness comparison among different retrieval techniques. They play an important role in advancing the state of the art in IR as proven by the TREC experiments (Voorhees, 2005; Voorhees \& Harman, 2005). Our document collection Milliyet, which has been developed for this study, is about $800 \mathrm{MB}$ in size and contains 408,305 news articles and 72 ad hoc queries written and evaluated by 33 assessors.

In effectiveness studies, stemming is a major concern (Harman, 1991). We compare the effects of four different stemming options on (Turkish) IR effectiveness. These are (a) no stemming, (b) simple word truncation, (c) the successor variety method (Hafer \& Weiss, 1974) adapted to Turkish, and (d) a lemmatizer-based stemmer for Turkish (Altintas \& Can, 2002; Oflazer, 1994). We investigate the IR effectiveness of these stemming options in combination with eight query-document matching functions. We also examine the impact of the use of a stopword list on effectiveness.

Since the performance of a search engine may not scale to large collections (Blair, 2002), we examine the scalability issues of our approach by testing on increasingly large portions of our collection.

To cover a wide range of IR application environments, we analyze the effects of query lengths on retrieval performance 
because an important possible difference in IR environments is query length (i.e., number of words used in queries). For example, in the Web environment, most information seekers use only a few words in their queries (Jansen \& Spink, 2006); however, the size of the requests sent to a commercial information system (e.g., West Publishing's WIN) is usually greater than two or three words (Thompson, Turtle, Yang, \& Flood, 1994). It also has been observed that the number of words in queries varies depending on the application area or increases due to collection-size growth (Blair \& Maron, 1985). As time passes, Web users tend to use more words in their queries (Semel, 2006).

In a similar way, we study how effectiveness varies with document length. In some environments, we may have short documents (e.g., image captions) while in others we may have long documents (e.g., full text of scientific papers). Different types of documents may have different retrieval characteristics (Robertson, 1981, p. 26; Savoy, 1999).

We hypothesize that within the context of Turkish IR, the following items would improve system performance in terms of higher retrieval effectiveness:

- the use of a stopword list in indexing (since they eliminate noise words from query and document representation),

- the use of language-specific stemming algorithms would scale better (since more accurate stems would reflect better document content, and this would be more noticeable in larger collections),

- longer queries (since they provide a better description of user needs), and

- longer documents (since the document contents may become more precise as we increase document sizes).

Our experiments are designed to test these hypotheses. Compared to previous studies on Turkish IR, our study includes a large-scale collection and a variety of retrieval scenarios.

Our contributions are summarized as follows. In this study, we construct the first large-scale Turkish IR test collection. Due to its size, we can argue that our results are generalizable. The publicly available version of this collection would provide an important, positive impact on Turkish IR research by offering a common denominator. Such collections open doors to research and development of languagespecific retrieval techniques for improved performance by comparative evaluation based on measurement (Voorhees, 2005); investigate the effects of numerous system parameters (e.g., stemming options, query-document matchingranking-functions, collection size, query lengths, document lengths) on Turkish IR, and provide valuable observations and recommendations for research and development.

In Table 1,we provide the meanings of frequently used acronyms. This is followed by a review of related works. Then we provide a quick overview of the Turkish language and the stemmers used in this study, and describe the experimental environment in terms of various stopword lists, query-document matching functions used for ranking documents, document collections, and queries. The experimental results given in the following section include the effectiveness
TABLE 1. Frequently used acronyms and their meanings.

\begin{tabular}{|c|c|c|c|}
\hline F3 . . F7 & $\begin{array}{l}\text { Fixed Prefix stemmers } \\
\text { (with prefix length } \\
\text { equal to } 3 \ldots 7 \text { ) }\end{array}$ & $\begin{array}{l}\text { MF1 . . } \\
\text { MF8 }\end{array}$ & $\begin{array}{l}\text { Matching Functions } \\
1 \ldots 8 \text {, see (Table } 2 \\
\text { for definitions) }\end{array}$ \\
\hline LM5 & $\begin{array}{l}\text { Lemmatizer-based } \\
\text { stemmer with average } \\
\text { stem length }=5\end{array}$ & NS & No Stemming \\
\hline LM6 & $\begin{array}{l}\text { Lemmatizer-based } \\
\text { stemmer with average } \\
\text { stem length }=6.58\end{array}$ & SV & $\begin{array}{l}\text { Successor Variety } \\
\text { stemmer }\end{array}$ \\
\hline LV & $\begin{array}{l}\text { LM5 stemmer, for words } \\
\text { with no lemma uses SV } \\
\text { for stemming }\end{array}$ & - & - \\
\hline
\end{tabular}

measure, stemming, matching function and scalability issues, stopword list, and query length and document length effects. We then provide a summary of our findings and future research directions.

\section{Related Work}

IR studies on languages other than English are less common. An incomplete list of such studies includes the works of Larkey, Ballesteros, and Connell (2002) on Arabic; Kettunen, Kunttu, and Jarvelin (2005) on Finnish; Savoy (1999) on French; Braschler and Ripplinger (2004) on German; Tordai and de Rijke (2006) on Hungarian; Asian, Williams, and Tahaghoghi (2004) on Indonesian; Popovic and Willett (1992) on Slovene; Figuerola, Gomez, Rodriguez, and Berrocal (2006) on Spanish; and Ahlgren and Kekalainen (2007) on Swedish. TREC involves limited non-English experiments for languages such as Arabic, Chinese, and Spanish (TREC, 2007; Voorhees, 2005). On the other hand, the Cross Language Evaluation Forum (CLEF, 2007) activity (Braschler \& Peters, 2004), whose document collection consists of more than 1.5 million documents in several European languages, is an important research effort with several achievements. Savoy (2006), for example, reported the effectiveness of various general stemming approaches for French, Portuguese, German, and Hungarian using the CLEF test collections. In the NII Test Collection for IR systems (NTCIR, 2007) evaluation campaign, the Chinese, Japanese, and Korean languages were studied.

The effect of stemming on IR effectiveness is an important concern (Frakes \& Baeza-Yates, 1992). The results are a "mixed bag." For example, Harman (1991), in her attempts with several stemming algorithms for English, was unable to succeed in improving the retrieval effectiveness. A similar observation has been reported for Spanish (Figuerola et al., 2006); however, for German for example, Braschler and Ripplinger (2004) showed the positive impact of stemming on retrieval effectiveness. Similarly, later studies on English have shown the positive impact of stemming on retrieval effectiveness (Hull, 1996; Krovetz, 1993). Stemming also is an important issue in Turkish IR studies. 
The earliest published Turkish IR study is by Köksal (1981) and uses 570 documents on computer science with 12 queries. It evaluates the effectiveness of various indexing and document-query matching approaches using recall-precision graphs. After experimenting with various prefix sizes, Köksal used the first five characters (5-prefix) of words for stemming.

Solak and Can (1994) used a collection of 533 news articles and 71 queries. The stemming algorithm of the Solak and Can study is based on looking for a given word in a dictionary, deleting a character from the end of the word, and then performing a structural analysis. The study shows 0 to $9 \%$ effectiveness improvement (in terms of precision at 10; i.e., P@10) with seven different query-document matching functions (corresponding to our matching functions MF1 to MF7, defined later).

Ekmekçioğlu and Willett (2000) used a Turkish news collection of 6,289 documents and 50 queries. They stemmed only query words (Document words are used as they are.), and compared the retrieval effectiveness using stemmed and unstemmed query words. In their study, a stemming-based query is effectively an extension of the unstemmed (i.e., original) query with various words corresponding to query word stems. They justified not stemming the documents words by stating that the roots of Turkish words are usually not affected with suffixes. Note, however, that no stemming for documents, depending on the term weighting scheme, can affect the term weights in documents and queries (Salton $\&$ Buckley, 1988). They showed that, using the OKAPI text retrieval system, their stemmed queries provide about $32 \%$ more relevant documents than that of unstemmed queries at the retrieval cut of values of (i.e., top) 10 and 20 documents. Their stemmer employed the same lemmatizer (Oflazer, 1994) that we used in the lemmatizer-based stemmer algorithm in this work.

Sever and Bitirim (2003) described the implementation of a system based on 2,468 law documents and 15 queries. First, they demonstrated the superior performance of a new stemmer with respect to two earlier stemmers (One of them is the Solak-Can stemmer mentioned earlier). Then they showed that their inflectional and derivational stemmer provides $25 \%$ retrieval precision improvement with respect to no stemming.

Pembe and Say (2004) studied the Turkish IR problem by using knowledge of the morphological, lexico-semantical, and syntactic levels of Turkish. They considered the effects of stemming with some query enrichment (i.e., expansion) techniques. In their experiments, they used 615 Turkish documents about different topics from the Web and five long, natural-language queries. They used seven different indexing and retrieval combinations, and measured their performance effects.

On the Web, there are several Turkish Web search engines and search directories (Can, 2006). Their quality and coverage vary. Bitirim, Tonta, and Sever (2002) investigated the performance of four Turkish Web search engines using 17 queries and measured their retrieval effectiveness, coverage, novelty, and recency.

\section{Stemming Methods for Turkish}

\section{Turkish Language}

In this study, by Turkish we mean the language mainly used in the republic of Turkey. The other dialects of Turkish, such as Azeri Turkish, are not our concern. Turkish belongs to the Altaic branch of the Ural-Altaic family of languages. Some concerns about this classification can be seen in Lewis (1988). The Turkish alphabet is based on Latin characters and has 29 letters consisting of 8 vowels and 21 consonants. The letters in alphabetical order are a, b, c, ç, d, e, f, g, 乌, h, $\mathbf{1}, \mathbf{i}, \mathrm{j}, \mathrm{k}, \mathrm{l}, \mathrm{m}, \mathrm{n}, \mathbf{o}, \ddot{\mathbf{o}}, \mathrm{p}$, $\mathrm{r}, \mathrm{s}, \mathrm{s}, \mathrm{t}, \mathbf{u}, \mathbf{u}, \mathrm{v}, \mathrm{y}$, and $\mathrm{z}$ (Vowels are shown in bold.). In some words borrowed from Arabic and Persian, the vowels "a," "i," and " $u$ " are made longer or softer by using the character ${ }^{\wedge}$ (circumflex accent) on top of them. In modern spelling, this approach is rarely used. In our collection, they occur in a few documents. The " (single quotation mark) is used to delimit the suffixes added to the proper names, such as in "Ali'nin evi İstanbul'da," which means "The house of Ali is in İstanbul."

Turkish is a free constituent order language (i.e., according to text flow and discourse context at certain phrase levels, its constituents can change order and still be intelligible; Lewis, 1988). For example, the sentence "İstanbul Ankara' dan daha güzel" (i.e., "İstanbul is more beautiful than Ankara.") and the sentence "Ankara'dan İstanbul daha güzel," which is an inverted sentence ("devrik cümle" in Turkish), have the same meaning with a slight difference in emphasis (Lewis, 1988).

Turkish is an agglutinative language similar to Finnish and Hungarian. Such languages carry syntactic relations between words or concepts through discrete suffixes and have complex word structures. Turkish words are constructed using inflectional and derivation suffixes linked to a root. Consider the following examples for two roots of type, respectively, "noun" and "adjective."

- Ev (house), evim (my house), evler (houses), evlerde (in houses), evlerim (my houses), evlerimde (in my houses), evimdeyken (while in my house).

- Büyük (large), büyükçe (slightly large), büyüklük (largeness).

The following is a Turkish word obtained from the verb type root "oku," which means "to read."

- Okutamayacakmışçasına (oku $+\mathrm{t}+\mathrm{ama}+$ yacak + mış + çasina) (as if not being able to make [them] read).

In these examples, the meaning of the roots are enriched through affixation of derivational and inflectional suffixes (The morphemes of the last example are shown and separated by + .) In Turkish, verbs can be converted into nouns and other forms, and nouns can be converted into verbs and other grammatical constructs, through affixation (Lewis, 1988).

In Turkish, the number of possible word formations obtained by suffixing can be as high as 11,313 (Hakkani-Tür, 2000, p. 31). Like other agglutinative languages, in Turkish it is possible to have words that would be translated into a complete sentence in nonagglutinative languages such as English; however, as we illustrate later, people usually do not use such words in their queries. 
Like English, nouns in Turkish do not have a gender and the suffixes do not change depending on word type; however, there are some irregularities in adding suffixes to the words. Since these irregularities affect the stemming, we provide the following examples (for more detailed information on the Turkish language and grammar, see Lewis, 1988). To obey the vowel harmony, different suffixes are used to obtain the same meaning. For example, "ev" (i.e., house) and "yer" (i.e., ground) take the "de" suffix and become "evde" (i.e., in the house) and "yerde" (i.e., on the ground) while "dağ" (i.e., mountain) and "bahar" (i.e., spring) take the "da" suffix and become "dağda" (i.e., on the mountain) and "baharda" (i.e., in the spring), respectively. In some words, the last consonant changes with some suffixes. For example, with the suffix "a," "ağaç" (i.e., tree) becomes "ağaca" (i.e., towards the tree) while with the suffix "da," the root does not change and becomes "ağaçta" (i.e., "on the tree"). In this example, note the transformation of "da" to "ta" due to the letter "ç." In some word and suffix combinations, the letters in the word may drop out. For example, with the suffix "um," the boldface letter $\mathbf{u}$ drops in "burun" (i.e., nose) and becomes "burnum" (i.e., my nose).

In Turkish, the only regular use of prefixation is to intensify the meaning of adjectives (and less commonly of adverbs), such as "dolu" (i.e., full) and "dopdolu," and "tamam" (i.e., complete) and "tastamam" (Lewis, 1988, pp. 55-56). Such intensive adjectives are more suitable for story telling, but not for news articles. Prefixation in old-fashioned words (e.g., "bîperva," which means "fearless") or prefixation coming from Western languages (e.g., "antisosyal," antisocial) are infrequent in the language.

\section{Stemming Methods}

We used four stemming methods in obtaining the indexing terms: (a) no stemming, the so-called austrich algorithm, (b) first $n, n$-prefix, and characters of each word; (c) the successor variety method adapted to Turkish, and (d) a lemmatizerbased stemmer.

No stemming. The no stemming (NS) option uses all words as an indexing term. The retrieval performance of this approach provides a baseline for comparison.

Fixed prefix stemming. The fixed prefix approach is a pseudostemming technique. In this method, we simply truncate the words and use the first $n$ characters of each word as its stem; words with less than $n$ characters are used with no truncation. We experimented with F3 to F7 $(3 \leq n \leq 7)$.

We include the fixed prefix method due to the observation that Turkish word roots are not affected much with suffixes (Ekmekçioğlu \& Willet, 2000). It is true that words in any language have roots with different lengths. Nevertheless, Sever and Tonta (2006) also suggested the use of the 5-, 6-, or 7-prefix for rapid and feasible Turkish IR system implementation. Their suggestion is intuitive and based on their observation that truncated and actual Turkish words display similar frequency distributions; however, they do not provide any IR experiments. As we indicated earlier, the use of prefixes is uncommon in Turkish. Therefore, in most cases, the fixed-prefix approach would truncate words with no prefixes. Note that the fixed-prefix approach is similar to the $n$ gram approach, but in a much simpler form since in the $n$-gram approach, the $n$-prefix is one of the $n$-grams that can be produced for a given word (McNamee \& Mayfield, 2004). For example, for the word "İstanbul," the F4 stemmer generates the string "ista" as the word stem, the 4-grams of the same word are "ista," "stan," "tanb," "anbu," and "nbul." For the word "bir" (i.e., one), which contains three characters, the F4 stemmer generates the word "bir" as its stem; similarly for this word, we have only one string generated by the 4-gram approach, and it is again the word "bir".

Successor variety stemming. The Successor Variety (SV) algorithm determines the root of a word according to the number of distinct succeeding letters for each prefix of the word can have in a large corpus (Frakes \& Baeza-Yates, 1992; Hafer \& Weiss, 1974). It is based on the intuition that the stem of a word would be the prefix at which the maximum SV is observed. For the working principles of the algorithm, please refer to the example provided in Frakes and Baeza-Yates (1992, p. 135). Our SV implementation chooses the longest prefix corresponding to the highest SV value (Note that the same SV value can be observed for various prefix sizes.) since longer stems would have a better reflection of the meaning of the complete word. Our SV algorithm directly returns the words that have a length less than four characters without applying the SVprocess.

Our SV algorithm implementation has further adaptations to Turkish. In Turkish, when a suffix is used, a letter may change into another one or may be discarded. For instance, the change of "ç" to "c" in our earlier example of "ağaç" and "ağaca" is an example of letter transformation. The earlier example of "burun" and "burnum" illustrates the second case since the letter $u$ drops. Another feature that can affect stemmers for Turkish is that there are compound words obtained by concatenating two words. For example, "hanımeli," which is a flower name, contains the words "hanım" and "eli," which mean "lady" and "hand," respectively. Finding "hanım" as the stem of "hanımeli" would be meaningless.

Our current SV algorithm only handles the letter-to-letter transformations, which are the most frequently seen characteristic among those just mentioned. When the algorithm detects a possibility of transformation, it checks for the probability if that transformation exists. The probabilities are calculated by using the distribution of corpus words that are related to transformations. If it is greater than a threshold value, then the prefix under consideration contributes to the SV count of the corresponding nontransformed prefix. For example, for "ağaca," the letter $a$ marked in bold contributes to the SV value of the stem (i.e., prefix) "ağaç." 
Lemmatizer-based stemming. A lemmatizer is a morphological analyzer that examines inflected word forms and returns their base or dictionary forms. It also provides the type (i.e., part of speech, POS, information) of these matches, and the number and type of suffixes (i.e., morphemes) that follow the matches. We used the morphological analyzer presented in Oflazer (1994). Note that lemmatizers are not stemmers since the latter obtains the root in which a word is based; in contrast, a lemmatizer tries to find the dictionary entry of a word. Being an agglutinative language, Turkish has different features from English. For English, stemming may possibly yield "stems" which are not real words. Lematization, on the other hand, tries to identify the "actual stem" or "lemma" of the word, which is the base form of the word that would be found in the dictionary. Due to the nature of English, sometimes words are mapped to lemmas, which apparently do not have any surface connection, as in the case of better and best being mapped to good; however, Turkish does not have such irregularities, and it is always possible to find the "stem" or "lemma" of any given word through application of grammar rules in removing the suffixes. For this reason, throughout the article, we prefer the word "stemming" over lemmatization, as it is more commonly used, and the algorithm we use internally identifies the suffixes and removes them in the stemming process.

In the lemmatization process in most of the cases, we obtained more than one result for a word; in such cases, the selection of the correct word stem is done by using the following steps (Altintas \& Can, 2002): (1) Select the candidate whose length is closest to the average stem length for distinct words for Turkish; and (2) If there is more than one candidate, then select the stem whose word type (i.e., POS) is the most frequent among the candidates.

For the aforementioned algorithm, we need to know the average type stem length, which was experimentally found as 6.58 by Altintas and Can (2002) by using a disambiguated large corpus and the word-type (i.e., POS) frequencies in Turkish. They showed that the success rate of the algorithm in finding the correct stems is approximately $90 \%$. Having a result of around $90 \%$ may be imperfect, but acceptable.

In this study, as the first algorithm parameter (i.e., the average stem length), we used 6.58 and 5 . We used the length 5 since as will be illustrated in the results section that the 5prefix provides the best effectiveness among the $n$-prefix methods. These two versions of the algorithm are referred to as LM5 and LM6. For various items, including misspelled and foreign words, which cannot be analyzed by the lemmatizer, in an additional LM5 version, we use the SV method for such words; this crossbreed is referred to as LV.

\section{Stopword Lists}

In IR, a stopword list contains frequent words that are ineffective in distinguishing documents from each other. In indexing, it increases the storage efficiency by eliminating the posting lists of such words from the indexing process; however, with the decreasing cost of secondary storage, this issue has lost its importance (Witten, Moffat, \& Bell, 1999). Dropping stopwords also can increase the query-processing efficiency. The construction of a stopword list involves various, sometimes arbitrary, decisions (Savoy, 1999).

In the IR literature, it is possible to find stopword lists with different lengths even for a given specific language. For English, Fox (1990) suggested a stopword list of 421 items, and the SMART system uses a list with 571 English "forms" (SMART, 2007). Commercial information systems tend to adopt a very conservative approach with only a few stopwords. For example, the DIALOG system is using only nine items (viz., "an," "and," "by," “for," "from," “of," "the," "to," and "with") (Harter, 1986).

In this study, we use three stopword lists. We first used a semiautomatic stopword-generation approach. For this purpose, we ranked all words according to their frequencies (i.e., total number of occurrences in all documents). Then, we determined a threshold value so that the words whose frequencies were above the threshold became a stopword candidate. In the manual stage, we removed some words selected thus far since they have information value (e.g., "Türkiye," and "Erdoğan;" i.e., current prime minister). We also added some variations of the selected words to the list and all letters of the Turkish alphabet and the letters $\mathrm{q}, \mathrm{w}$, and $\mathrm{x}$. The semiautomatically generated stopword list contains 147 words and is given in Appendix Table A1, in alphabetical order to see variations of some words. The stopword list covers $14 \%$ of all word occurrences in documents when no stemming is used.

We also experimented with a second stopword list and just used the top most frequent 288 words with no elimination. When we listed the words, we observed that the top words covered a significant fraction of all word occurrences, but this coverage begins to disappear as we include more words on the stoplist. After observing this, we stopped including such words to the list. This process gives 288 words, and they cover $27 \%$ of all word occurrences. The second set is used to understand the retrieval-effectiveness consequences of automatic construction of stopword lists in Turkish.

As an extreme case, we also experimented with a short stopword list that contains the most frequent first 10 words ("ve" "bir," "bu," “da," "de," "için," "ile," "olarak," “çok," and "daha;" their meanings in order are "and," "a/an/one," "this," "too," “too," “for," "with," “time," "very," and "more"). The word "olarak" is usually used in phrases such as "ilk olarak/for the first time," and "son olarak/ for the last time). These words cover $8 \%$ of all word occurrences.

\section{Matching (Ranking) Functions}

Assigning weights to terms in both documents and queries is an important efficiency and effectiveness concern in the implementation of IR systems (Cambazoglu \& Aykanat, 2006; Lee, Chuang, \& Seamons, 1997). In this study, for term weighting we use the $t$ f.idf model. Term weighting has three components: term frequency component (TFC), collection frequency component (CFC), and normalization 
component (NC). The weights of the terms of a document and a query (denoted by $\mathrm{w}_{\mathrm{dk}}$ and $\mathrm{w}_{\mathrm{qk}}, 1 \leq k \leq$ no. of terms; i.e., the number of terms used in the description of all documents) are obtained by multiplying the respective weights of these three weighting components. After obtaining the term weights, the matching function for a document (Doc) and a query $(\mathrm{Q})$ is defined with the following vector product (Salton \& Buckley, 1988):

$$
\operatorname{similarity}(\operatorname{Doc}, Q)=\sum_{k} w_{d k} \cdot w_{q k}
$$

In ranking-based text retrieval, documents are ranked according to their similarity to queries. The weight $\mathrm{w}_{\mathrm{dk}}$ of term $t_{k}$ in Doc is defined by the following product (TFC \& times; $\mathrm{CFC} \times \mathrm{NC}$ ). The three possibilities for TFC are symbolized by $b, t$, and $n$, and correspond to $t f$ of the well-known $t f . i d f$ indexing approach in IR (Witten et al., 1999). In TFC, $b$ is binary weight; in this case, ignore the term frequency and take $\mathrm{TFC}=1 ; t$ is term frequency, which means that TFC is equal to the number of occurrences of $t_{j}$ in $d_{i} ; n$ is the augmented normalized term frequency and is defined as $0.5+$ $0.5 \times t / \max t$, where $\max t$ is the maximum number of times any term appears in $\mathrm{d}_{\mathrm{i}}$.

The three possibilities for CFC are denoted by $x, f$, and $p$. In $\mathrm{CFC}, x$ indicates no change (i.e., take $\mathrm{CFC}=1$ ). The symbol $f$ indicates the inverse document frequency, $i d f$, and in this study it is taken as $\ln \left(N / t_{g j}\right)+1$ for document and query terms; $N$ is total number of documents in the collection, and $t_{g j}$ is the number of documents containing $t_{j}$. The symbol $p$ is the probabilistic inverse collection frequency factor, and it is similar to $f$ both in terms of definition and performance (Salton $\&$ Buckley, 1988). We did not use it in our experiments.

For normalization (i.e., the NC component) there are two possibilities, denoted by $x$ and $c$. The symbol $x$ means no change (i.e., take $\mathrm{NC}=1$ ); $c$ means cosine normalization where each term weight $(\mathrm{TFC} \times \mathrm{CFC}$ ) is divided by a factor representing Euclidian vector length. The normalization of query terms is insignificant since it does not change the relative ranking of documents.

Various combinations of the term weighting components yield different matching functions (i.e., index structures as given in Table 2). For example, MF1 [i.e., the combination $t x c(\mathrm{TFC}=t, \mathrm{CFC}=x$, and $\mathrm{NC}=c)$ and $t x x$, respectively, for documents and queries yield the well-known cosine function with no idf component; it simply uses document and query vectors as they are. The combinations $t f c$ and $n f c$ for documents and $n f x$, $t f x$, and $b f x$ for queries have been determined to result in better IR performance. These provide us with the six different matching functions (MF2-MF7):

TABLE 2. Matching (ranking) functions used in the experiments.

\begin{tabular}{lccccccc}
\hline $\begin{array}{l}\text { Matching } \\
\text { function }\end{array}$ & MF1 & MF2 & MF3 & MF4 & MF5 & MF6 & MF7 \\
\hline Meaning & txc.txx & $t f c . n f x$ & $t f c . t f x$ & $t f c . b f x$ & $n f c . n f x$ & $n f c . t f x$ & $n f c . b f x$ \\
\hline
\end{tabular}

"tfc.nfx," "tfc.tfx," "tfc.bfx," "nfc.nfx," "tfc.tfx," and "nfc.bfx." These are similar, but different, document-query matching functions and are highly recommended by Salton and Buckley (1988). Table 2 shows these seven combinations (i.e., the query matching functions used in our experiments). These are the matching functions that we have used in previous studies for information retrieval in English (Can \& Ozkarahan, 1990) and Turkish (Solak \& Can, 1993) texts.

Additionally, we used MF8 (Long \& Suel, 2003; Witten et al., 1999). $M F 8$ calculates matching value for document $d_{j}$ for the Search Query $Q$ as follows:

$$
M F 8=\sum_{t \in Q}\left(\left(1+\ln f_{d t}\right) / \sqrt{D}\right) \cdot\left(f_{q t} \cdot \ln \left(1+N / f_{t}\right)\right)
$$

where $f_{d t}$ is the frequency of Term $t$ in Document $d_{j}, D$ is the total number of term occurrences in $d_{j}, f_{q t}$ is the frequency of Term $t$ in the Query $Q$, as defined previously $N$ is the total number of documents, and $f_{t}$ is the frequency of Term $t$ in the entire document collection. Note that $M F 8$ is especially suitable for dynamic environments since in dynamic collections one can easily reflect the effects of $i d f$ to the term weighting scheme via query term weights (the second item of the MF8 formula).

\section{Test Collection}

Our document collection contains 408,305 documents; they are the news articles and columns of 5 years (2001-2005) from the Turkish newspaper Milliyet (www.milliyet.com.tr). The size of the Milliyet 2001-2005 (hereafter, Milliyet) collection is about $800 \mathrm{MB}$, and without stopword elimination, each document contains 234 words (tokens) on the average. It contains about 95.5 (89.46 alphabetic, 4.66 numeric, and 1.36 alphanumeric) million words before stopword elimination. We converted all uppercase letters to their smallcase equivalents and used UTF-8 for character encoding. The ' (i.e., quotation mark) and - (i.e., -) are considered as part of a word unless they are the last character. The letters "a," "i," and "u" with the character ${ }^{\wedge}$ on top of them are taken as distinct letters than their counterparts. The average word (i.e., token) length is 6.90 characters.

The indexing information with different stemmers, using the Appendix Table A1 stopword list, is shown in Table 3. After stopword elimination, each document contains 201 words (i.e., tokens), on average. When NS is used, each document contains 148 terms (unique words; i.e., types), on average. In this table, "total number of terms" indicates the number of unique words in the collection. The table also contains various information on term lengths. The longest meaningful word in the whole collection is the word "Danimarkalılaştıramadıklarımızdan." It contains 33 characters and means "he (she) is one of those who we were unable to convert to Danish." However, note that such words are uncommon, as illustarted by Figure 1. This figure shows the total number of unique terms with a certain length for all stemming options. For F5 and F6, there is no observation after five and six characters, respectively. 
TABLE 3. Indexing information with the stopword list provided in Appendix Table A.1

\begin{tabular}{lrrrrr}
\hline Information & NS & F5 & F6 & SV & LV \\
\hline Total no. terms & $1,437,581$ & 280,272 & 519,704 & 418,194 & 434,335 \\
Average no. & 148 & 124 & 132 & 119 & 117 \\
$\quad$ terms/document & & & & & \\
Average term length & 9.88 & 4.82 & 5.66 & 7.23 & 7.24 \\
Median term length & 9 & 5 & 6 & 7 & 7 \\
Minimum term length & 2 & 2 & 2 & 2 & 2 \\
Maximum term length & $50^{*}$ & 5 & 6 & $46^{*}$ & $46^{*}$ \\
$S D$ for term length & 3.58 & 0.50 & 0.69 & 2.74 & 2.71 \\
No. posting elements & 60 & 51 & 54 & 48 & 48 \\
$\quad$ (millions) & & & & & \\
Storage efficiency & N/A & $15 \%$ & $10 \%$ & $20 \%$ & $20 \%$ \\
$\quad$ with respect to NS & & & & & \\
\hline
\end{tabular}

*Do not correspond to actual words due to errors such as missing blank spaces, etc.

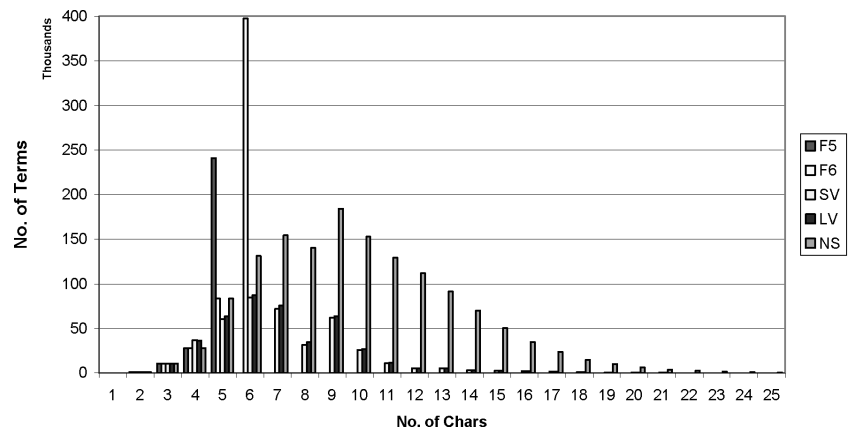

FIG. 1. Term frequency versus term length (in characters) for all stemmers.

The posting lists sizes with different stemming options, in terms of <word, word frequency $>$ pair, which also are shown in Table 3. These values for NS, F5, and LV are 60, 51, and 48 million entries, respectively. This means that F5 and LV provide $15 \%$ (51 vs. 60 ) and $20 \%$ (48 vs. 60 ), respectively, storage efficiency with respect to NS. Without stopword elimination, the posting lists contain 67 million entries.

The queries are written and evaluated according to the TREC approach by 33 native-speaker assessors. The original query owners do the evaluation using binary judgment. Relevant documents are identified by examining the union of the top 100 documents of the 24 possible retrieval combinations (i.e., "runs") of the eight matching functions and the stemmers NS, F6, and SV that we had at the beginning of our experiments.

For determining the relevant documents of the queries, the pooling concept is used (Zobel, 1998). During evaluation, the query-pool contents are presented to the assessors (i.e., the query owners) in random order, and the rest of the collection is assumed to be irrelevant. The assessors use a Web interface for query evaluation. All assessors are experienced Web users: graduate and undergraduate students, faculty members, and staff. They are allowed to query any information need that they choose and are not required to have an expertise on the topic that they pick. The query subject categories and the number of queries in each category are shown in Appendix Table A2.

A typical query is a set of words that describes a user information need with three fields: topic (a few words), description (one or two sentences), and narrative (more explanation). The topics of all queries and the number of relevant documents for each query are listed in Appendix Table A3. The query topics cover a wide range of subjects and are distributed to all 5 years covered by the collection.

During pooling, for the construction of the query vectors, only the topic and description fields have been used. The average pool size and relevant documents per query are 466.5 and 104.3, respectively. We have 72 queries after eliminating 20 queries with too few ( $\leq 5 \%$ of its pool) or too many ( $\geq 90 \%$ of its pool) relevant documents in their pools: It is known that such queries are not good at discriminating retrieval systems (Carterette, Allan, \& Sitaraman, 2006). A typical query evaluation takes about $130 \mathrm{~min}$. The total number of documents and unique documents identified as relevant are 7,510 and 6,923, respectively.

In the rest of this article, we will refer the query forms made of Topic as Qs (i.e., short query), Topic +Description as $\mathrm{Q}_{\mathrm{M}}$ (i.e., medium-length query), and Topic + Description+ Narrative as $\mathrm{Q}_{\mathrm{L}}$ (i.e., long query). Tables 4 and 5, show the query and query word length statistics, respectively, for the queries. Note that from short to long queries, the variety of the words (i.e., number of unique words) and the average length of both words and unique words increase.

The most frequently used top 10 words in the $\left(\mathrm{Q}_{\mathrm{M}}\right)$ queries are "türkiye'de," "etkileri," "üzerindeki," "türk," "gelen," "son," "türkiye," "avrupa," "meydana," and "şiddet." These words account for $10.26 \%$ of all word occurrences of 1,004 query words. The frequently used query words are short; actually, this is true for all query words. They are not like extreme Turkish word examples; such as “Avrupalılaştııılamayabilenlerdenmişsiniz," which means

TABLE 4. Query statistics.

\begin{tabular}{lrrrc}
\hline Entity & Min. & Max. & $M d n$ & Average \\
\hline $\begin{array}{l}\text { Pool Size (no. unique } \\
\quad \text { documents) }\end{array}$ & 186 & 786 & 458 & 466.5 \\
$\begin{array}{l}\text { No. relevant documents } \\
\quad \text { in query pools }\end{array}$ & 18 & 263 & 93 & 104.3 \\
$\begin{array}{l}\text { Query evaluation time* (min) } \\
\text { No. unique words in } \mathrm{Q}_{\mathrm{S}}{ }^{* *}\end{array}$ & 60 & 290 & 120 & 132.4 \\
No. unique words in $\mathrm{Q}_{\mathrm{M}}{ }^{* *}$ & 1 & 7 & 3 & 2.89 \\
No. unique words in $\mathrm{Q}_{\mathrm{L}}{ }^{* *}$ & 5 & 24 & 11 & 12.00 \\
\hline
\end{tabular}

*Entered by participants. ** With stopwords.

TABLE 5. Query word statistics.

\begin{tabular}{lccr}
\hline Entity & $\mathrm{Qs}_{\mathrm{s}}$ & $\mathrm{Q}_{\mathrm{M}}$ & \multicolumn{1}{c}{$\mathrm{Q}_{\mathrm{L}}$} \\
\hline No. words & 208 & 1,004 & 2,498 \\
No. unique words & 182 & 657 & 1,359 \\
Average word length & 7.03 & 7.57 & 7.62 \\
Average unique word length & 7.00 & 7.75 & 8.04 \\
\hline
\end{tabular}


"you seem to be one of those who may be incapable of being Europeanized" (Ekmekçioğlu \& Willet, 2000). From Q $\mathrm{Q}_{\mathrm{L}}$, query words become slightly longer (see Table 5) as users are given the opportunity of expressing their information needs in more detail in narrative form.

\section{Experimental Results}

\section{Effectiveness Measures}

Precision and recall are the most commonly known effectiveness measures in IR. They are, respectively, defined as the proportion of retrieved documents that are relevant, and the proportion of relevant documents retrieved. Recall is difficult to measure in real environments. Precision at the top 10 and 20 documents (P@10, P@20) are sometimes the preferred measure because of their simplicity and intuitiveness. Furthermore, in the Web environment search engine users usually look only at the top two pages, and P@10 and P@20 reflect the user satisfaction. However, mean average precision (MAP), which is the mean of the average precision value when a relevant document is retrieved, is considered as a more reliable measure for effectiveness (Buckley \& Voorhees, 2004; Sanderson \& Zobel, 2005; Zobel, 1998).

In our case, as we indicated earlier, the query pools (used in determining the relevant documents) are constructed by using the stemmers NS, F6, and SV; however, these relevance judgements also are used for the evaluation of systems (i.e., "stemmer and matching function") combinations that are not used in the construction of the query pools. This may be a disadvantage for such systems due to a possible bias. For such cases, Buckley and Voorhees (2004) introduced a new measure called "binary preference" or bpref, that ignores the documents not evaluated by users. For this reason, we used the bpref measure for performance measurement. We use the trec-eval package Version 8.1 for obtaining the effectiveness measures. When necessary, we conducted twotailed $t$ tests for statistical analysis using an alpha level of 0.05 for significance.

\section{Selection of Stemmers for Overall Evaluation}

To streamline the overall evaluation process, first we determined the best representative of the fixed prefix and the lemmatizer-based methods. Table 6 shows the assessment of all fixed prefix methods according to different effectiveness measures with the matching function $M F 8$ that gives the best

TABLE 6. Various effectiveness measure results with $M F 8$ and $\mathrm{Q}_{\mathrm{M}}$ for fixed prefix methods F3 to F7.

\begin{tabular}{lllll}
\hline Method & bpref & MAP & P@ 10 & P@ 20 \\
\hline F3 & .4120 & .3134 & .5139 & .4757 \\
F4 & .4382 & .4013 & .5625 & .5361 \\
F5 & .4322 & .4092 & .5917 & .5653 \\
F6 & .4014 & .3885 & .5667 & .5382 \\
F7 & .3901 & .3658 & .5556 & .5181 \\
\hline
\end{tabular}

performance for all stemmer and matching function combinations. In terms of bpref, F4 and F5 are better than the rest (e.g., 5-6\% better than F3). For choosing only one of these matching functions, we also considered the MAP, P@10, and P@20 values. In terms of MAP measure, the performance of F5, which is not used in the construction of query pools, is $5 \%$ better than that of F6 (the only fixed prefix method used in constructing the query pools). The same is approximately true for F4. According to the MAP results, F3 and F7 are obvious losers. The bpref and MAP values of F4 and F5 are close to each other; on the other hand, P@10 and P@20 values of F5 are about 5\% higher than that of F4. Due to these observations, we used F5 as the representative of the fixed prefix stemmers. However, note that the twotailed $t$ test results indicate no statistically significant difference between F4 and F5 with MF8 using P@10 and P@20 individual query results.

In a similar fashion, LM5 is slightly better than LM6. As a lemmatizer-based stemmer, we also have LV that takes advantage of LM5 and SV. LV shows slightly, but not significantly, better performance than LM5. As a result, for the final analysis we have NS, SV, F5 (the representative for the fixed prefix methods), and LV (the representative for the lemmatizer methods).

\section{Overall Evaluation: Effects of Stemming and Matching Functions}

Table 7 shows the performance of NS, SV, F5, and LV (We also include LM5 for comparison with LV.) in terms of bpref. The table also shows the percentage performance improvement of LV, SV, and F5 with respect to NS, and the improvement provided by LV with respect to SV and F5. For easy comparison, bpref values of NS, F5, SV, and LV are shown as bar charts in Figure 2. In terms of $M F 8$, which provides the best performance with all matching functions, Stemming Methods F5, LV, and SV provide $32.78,38.37$, and $32.23 \%$, respectively, better performance than that of NS. These are all statistically significant improvements $(p<.001)$.

In our IR experiments, the most effective stemming method was LV. The performance comparison of F5, LV, and $\mathrm{SV}$ in terms of MF8 (Table 7) shows that LV is slightly, $4.65 \%$ and $4.21 \%$, better than SV and F5 (see the LV/SV and LV/F5 columns); however, these differences are statistically insignificant. The SV method and the simple prefix method F5 also are effective, but not as effective as LV; and F5 is slightly better than SV. The LV stemmer performs slightly better than F5; however, the difference is statistically insignificant.

The comparisons of F5, LV, and SV with the average results of the matching functions $M F 1$ through $M F 8$ (using the corresponding eight average bpref values given in the columns of Table 7) show no statistically significant difference between F5 and SV, but do show a significant difference between F5 and LV, and SV and LV using two-tailed $t$ tests $(p<.001)$. Note that these comparisons are based on the average bpref values listed in Table 7 (i.e., the column-wise comparison of the eight bpref values (corresponding to 
TABLE 7. Bpref values of NS to LM5 and \%improvement of LV with respect to NS (LV/NS) to LV with respect to F5 (LV/F5) using query form QM and matching functions MF1 through MF8.

\begin{tabular}{|c|c|c|c|c|c|c|c|c|c|c|}
\hline \multirow[b]{2}{*}{ MF } & \multicolumn{5}{|c|}{ bpref } & \multicolumn{5}{|c|}{ \%Improvement } \\
\hline & NS & F5 & SV & LV & LM5 & LV/NS & SV/NS & $\mathrm{F} 5 / \mathrm{NS}$ & $\mathrm{LV} / \mathrm{SV}$ & LV/F5 \\
\hline MF1 & .2452 & .3108 & .3046 & .3339 & .3275 & 36.18 & 24.23 & 26.75 & 9.62 & 7.43 \\
\hline MF2 & .3124 & .3961 & .4096 & .4175 & .4095 & 33.64 & 31.11 & 26.79 & 1.93 & 5.40 \\
\hline MF3 & .3045 & .3823 & .3908 & .4054 & .3992 & 33.14 & 28.34 & 25.55 & 3.74 & 6.04 \\
\hline MF4 & .3099 & .3905 & .4030 & .4122 & .4045 & 33.01 & 30.04 & 26.01 & 2.28 & 5.56 \\
\hline MF5 & .2849 & .3764 & .3663 & .3890 & .3805 & 36.54 & 28.57 & 32.12 & 6.20 & 3.35 \\
\hline MF6 & .2982 & .3883 & .3678 & .3908 & .3847 & 31.05 & 23.34 & 30.22 & 6.25 & 0.64 \\
\hline MF7 & .2692 & .3532 & .3477 & .3734 & .3642 & 38.71 & 29.16 & 31.20 & 7.39 & 5.72 \\
\hline MF8 & .3255 & .4322 & .4304 & .4504 & .4447 & 38.37 & 32.23 & 32.78 & 4.65 & 4.21 \\
\hline Collection average & .2854 & .3715 & .3675 & .3922 & .3861 & 35.08 & 28.38 & 28.93 & 5.26 & 4.79 \\
\hline
\end{tabular}

$\mathrm{MF}=$ matching functions, $\mathrm{NS}=$ no stemming, $\mathrm{SV}=$ Successor Variety, $\mathrm{LV}=$ crossbreed

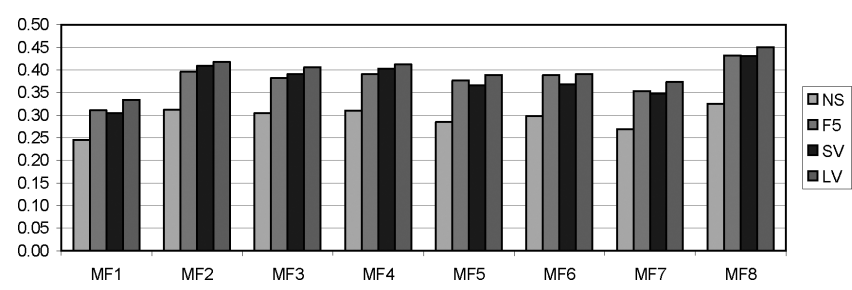

FIG. 2. Bpref values of NS, F5, SV, and LV with matching functions $M F 1$ to $M F 8$ using $\mathrm{Q}_{\mathrm{M}}$.

$M F 1-M F 8$ ) for $\mathrm{F} 5, \mathrm{LV}$, and $\mathrm{SV}$; however, comparison of these methods by using the individual bpref values of the queries for a given matching function (e.g., $M F 8$ results with F5 and LV) show no statistically significant difference using two-tailed $t$ tests. These results show that a simple word-truncation approach (F5) and a careful word-truncation approach that uses language-dependent corpus statistics (SV) and a sophisticated lemmatizer-based stemmer (LV) provide comparable retrieval effectiveness. This is conceptually in parallel with the findings of a study on another agglutinative language: Kettunen et al. (2005) showed that for Finnish, a lemmatizer and a simple (Porter-like) stemmer provide retrieval environments with similar effectiveness performances.

Our results show that $M F 1$ was the poorest performer. This can be explained by the lack of the idf component in its definition. $M F 2$ outperformed the other matching functions, except MF8. Similar results have been reported elsewhere (Can \& Ozkarahan, 1990) about the performance of $M F 1$ to $M F 7$. The relative performances of these matching functions are consistent in this and the aforementioned study. Our results show that $M F 8$, which involves no (document) term reweighting due to addition or deletion of documents, gave the best performance. This has practical value in dynamically changing real environments.

In the following sections, for performance comparison, we use the results of $M F 8$ (i.e., the matching function that provides the best performance), and only consider NS, F5, and $\mathrm{LV}$ due to comparable performances of F5 and SV.

\section{Effects of the Stopword List on Retrieval Effectiveness}

In this section, we analyze the effects of the stopword list on retrieval effectiveness. In the first set of experiments, we measured bpref values using the semimanually constructed stopword list (Appendix Table A1) and without using a stopword list. The results presented in Table 8 along with twotailed $t$ tests show that stopword lists have no significant impact on performance. Note that the assessors (i.e., query owners) are told nothing about the use of frequent Turkish words; nevertheless, such words have not been used heavily in the queries. For example, in $\mathrm{Q}_{\mathrm{M}}$ a query contains 1.74 stopwords, on average.

In the aforementioned approach, we use the stopword list to eliminate words before entering them to the stemmers. As an additional experiment, we have used the stopword list after stemming. For this purpose, we first used the F5 stemmer to find the corresponding stem, then we searched the stemmed word in the stemmed stopword list. The experiments again show no statistically significant performance change.

To observe the possible effects of automatic stopword list generation, we also used the automatically generated stopword lists of the most frequent 288 words, and 10 words. The IR effectiveness performance with them is not statistically significantly different from the case with no stopword list.

From these observations, we conclude that the use of a stopword list has no significant effect on Turkish IR performance; however, note that this may be a result of the tf.idf model we used. For example, Savoy (1999) reported experiments on French text in which the stopword list did not have any influence with the tf.idf model but did have influence with the OKAPI model. Our results are consistent with his observations.

TABLE 8. Bpref values using $\mathrm{Q}_{\mathrm{M}}$ with (NS, F5, LV) and without (NS', F5', LV') a stopword list.

\begin{tabular}{lccccc}
\hline NS & NS' & F5 & F5' & LV & LV' $^{\prime}$ \\
\hline 0.3255 & 0.3287 & 0.4322 & 0.4330 & 0.4504 & 0.4524 \\
\hline
\end{tabular}




\section{Scalability}

Scalability is an important issue in IR systems due to the dynamic nature of document collections. For this purpose, we have created eight test collections in 50,000 document increments of the original test collection. The first increment contains the initial 50,000 documents (in temporal order) of the Milliyet collection; the second one contains the first 100,000 documents and is a superset of the first increment. The final step corresponds to the full version of the document collection.

For evaluation, we used the queries with at least one relevant document in the corresponding incremental collection. For example, for the first 50,000 documents we have 57 active queries (i.e., queries with at least one relevant document in the first 50,000 documents). Table 9 shows that each increment has similar proportional query-set characteristics; for example, the median number of relevant documents per query increases approximately 10 by 10 (11.0, 21.5, 34.0, etc.) at each collection-size increment step. This means that experiments are performed in similar test environments.

Understanding the retrieval environments in more detail might be of interest. The characteristics of the collections as we scale up are shown graphically in Figures 3 and 4. Figure 3 shows that the number of unique words increases with the increasing collection size; however, F5 and LV show saturation in the increase of unique words as we increase the number of documents, and this is more noticeable with F5. Figure 4 shows that the number of postings (i.e., $<$ document number, term weight $>$ pairs or tuples) in the inverted files of NS, F5,

TABLE 9. Query relevant document characteristics for increasing collection size.

\begin{tabular}{lcccc}
\hline No. & Notal no. & $\begin{array}{c}\text { Average no. } \\
\text { unique } \\
\text { relevant } \\
\text { rocuments } \\
\text { documents } \\
\text { queries }\end{array}$ & $\begin{array}{c}\text { Mdn no. } \\
\text { relevant } \\
\text { documents } \\
\text { /query }\end{array}$ \\
\hline 50,000 & 57 & 719 & 10.72 & 11.0 \\
100,000 & 62 & 1380 & 21.08 & 21.5 \\
150,000 & 63 & 2014 & 30.55 & 34.0 \\
200,000 & 64 & 2944 & 44.33 & 45.5 \\
250,000 & 68 & 3764 & 56.51 & 56.5 \\
300,000 & 70 & 4794 & 71.45 & 66.0 \\
350,000 & 71 & 5725 & 86.29 & 79.0 \\
408,305 & 72 & 6923 & 104.30 & 93.0 \\
\hline
\end{tabular}

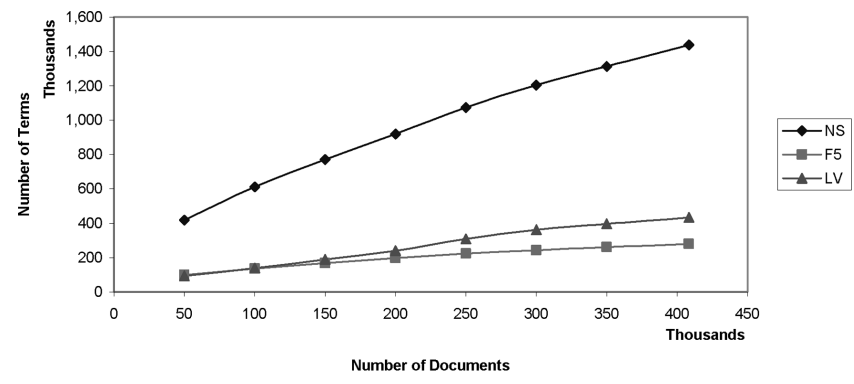

FIG. 3. Indexing vocabulary size versus collection size.

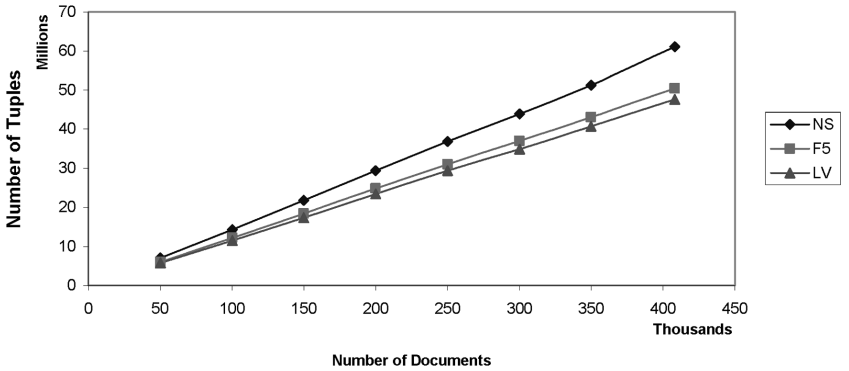

FIG. 4. Number of posting list tuples versus collection size.

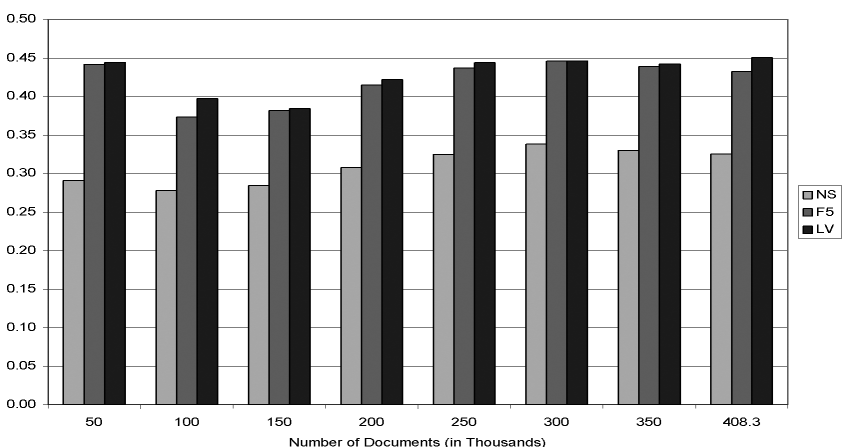

FIG. 5. Bpref values with $M F 8$ for NS, F5, and LV using $\mathrm{Q}_{\mathrm{M}}$ as collection size scales up.

and LV linearly increases as we increase the collection size. The graphical representation of posting list sizes of this figure indicates that with NS we have many short posting lists.

The performance of NS, F5, and LV in terms of bpref as we scale up the collection is presented in Figure 5. With the first increment, we have a relatively better performance with respect to the performances of the next three steps. In the second incremental step (i.e., with 100,000 documents), we have a decrease in performance, then performance tends to increase. Beginning with 250,000 documents, we have a steady retrieval performance. This can be attributed to the fact that after a certain growth, document-collection characteristics reach a steady state.

In this work, our concern is the relative performances of NS, F5, and LV. We see that matching functions show steady relative-effectiveness performances. Contrary to our initial hypothesis, the LV stemmer, which is designed according to the language characteristics, shows no improved performance as the collection size increases: The simple term truncation methods of F5 and LV are compatible with each other in terms of their retrieval-effectiveness performances throughout all collection sizes. LV provides slightly better, but statistically insignificant, performance improvement with respect to F5; however, the performance of F5 and LV with respect to NS is statistically significantly different $(p<.001)$.

\section{Query Length Effects}

In an IR environment, depending on the needs of the users, we may have queries with different lengths. For this reason, we analyze the effects of query lengths on effectiveness. 


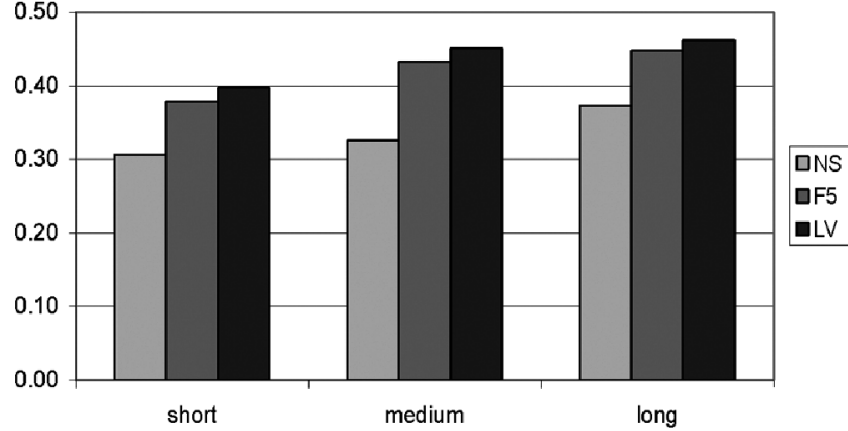

FIG. 6. Bpref values with various query lengths using $M F 8$.

The query types according to their lengths are described in our test-collection discussion (see Tables 4 and 5).

The experimental results are summarized in Figure 6. The figure shows that as we go from $\mathrm{Q}_{\mathrm{S}}$ to $\mathrm{Q}_{\mathrm{M}}$, we have a statistically significant $(p<.01)$ increase in performance using F5 and LV. Improvements in effectiveness for them, respectively, are 14.4 and $13.5 \%$. The tendency of performance to increase can be observed as we go from $\mathrm{Q}_{\mathrm{M}}$ to $\mathrm{Q}_{\mathrm{L}}$, but this time the increase is statistically insignificant. For all query cases under the same query form, the performance difference of F5 and LV is statistically insignificant; however, the performance difference of these stemmers with respect to NS is statistically significant $(p<.001)$. (The findings stated in the last two sentences were presented before for only $\mathrm{Q}_{\mathrm{M}}$; here, we provide the observations for the other two query forms $\mathrm{Q}_{S}$ and $\mathrm{Q}_{\mathrm{L}}$.) In terms of NS, the performance increase is first $6.23 \%$ and then $14.59 \%$ as we increase the query lengths incrementally. The second increase is statistically significant $(p<.01)$. In other words, NS gets more benefit from query length increase. In addition, the negative impact of not being stemmed is partly recovered with the increase in query length. From the experiments, we observe that there is no linear relationship between query length and retrieval effectiveness. That is, as we increase the query length, we first have improvement, but after an increase of a certain length this effectiveness increase tends to saturate; however, the NS approach improves its performance as we increase the query length.

The effectiveness improvement can be attributed to the fact that longer queries are more precise and provide better description of user needs. Similar results have been reported in other studies regarding the effects of increasing query length. For example, Can, Altingovde, and Demir (2004) reported similar results for increasing query length with the Financial Times TREC collection.

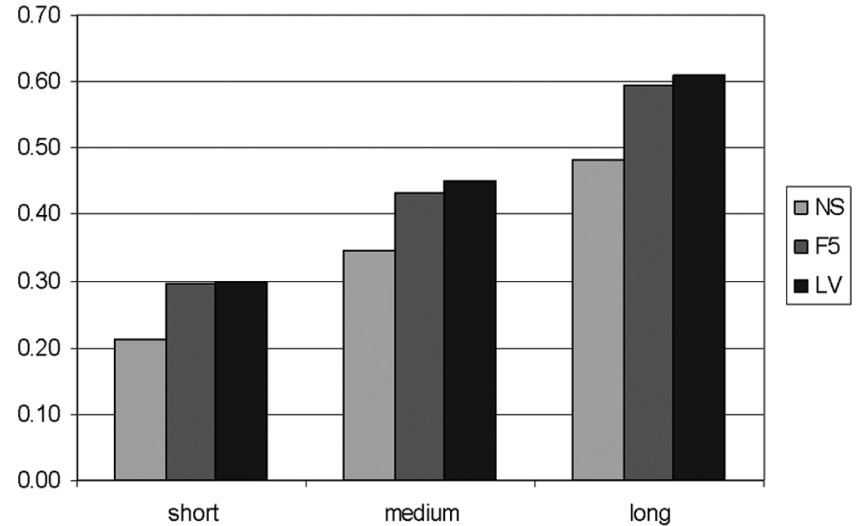

FIG. 7. Query characteristics and bpref values with $M F 8$ using $\mathrm{Q}_{\mathrm{M}}$ for different document-length collections.

\section{Document Length Effects}

In different application environments, it is possible to have documents with different lengths. For this reason, we divided the Milliyet collection according to document length and obtained three subcollections that consist of short (i.e., documents with maximum 100 words), medium length (i.e., documents with 101-300 words), and long documents (i.e., documents with more than 300 words). In a similar fashion, we divided the relevant documents of the queries among these subcollections as we did in the scalability experiments. Table 10 shows that most of the relevant documents are associated with the collection with mediumsized documents. This can be explained by its size: It contains almost half of the full collection.

In the experiments, we use the query form $\mathrm{Q}_{\mathrm{M}}$. The graphical representation of bpref values in Figure 7 shows that as the document sizes increase, the effectiveness in terms of bpref values significantly increases $(p<.001)$; this is true for all stemming options. We have no objective analysis of the average number of topics per news articles of the Milliyet collection; however, it is our anecdotal observation that in the overwhelming majority of the news articles, only one topic is covered. Hence, the persistent increase in effectiveness as the document length increases can be attributed to the fact that longer documents provide better evidence about their contents and hence better discrimination during retrieval. Our result of having better performance with longer documents (e.g., news articles) is consistent with the findings of Savoy (1999, Tables 1a and 1b; Appendix Table A1); however, note that when document size increases, document representatives could be more precise until a given limit. After this point, we may expect to see the inclusion of more details or nonrelevant aspects (under

TABLE 10. Document collection characteristics for documents with different lengths.

\begin{tabular}{|c|c|c|c|c|c|}
\hline Collection document type & No. documents & No. active queries & $\begin{array}{l}\text { Total no. unique } \\
\text { relevant documents }\end{array}$ & $\begin{array}{c}\text { Average no. relevant } \\
\text { documents/query }\end{array}$ & $\begin{array}{l}M d n \text { no. relevant } \\
\text { documents/query }\end{array}$ \\
\hline Short & 139,130 & 72 & 1,864 & 27.50 & 18.5 \\
\hline Medium & 193,144 & 72 & 3,447 & 52.14 & 45.0 \\
\hline Long & 76,031 & 72 & 1,612 & 24.67 & 21.0 \\
\hline
\end{tabular}


the implicit assumption of a newspaper corpus). Thus, longer documents could hurt the retrieval performance in such cases.

In the experiments, for all document-length cases, the performance difference of F5 and LV is statistically insignificant; however, the performance difference of these stemmers with respect to NS is statistically significant $(p<.001)$. These observations confirm our previously stated findings for these stemmers, but in different types of documents in terms of their lengths.

\section{Conclusions and Future Research}

In this study, we provide the first thorough investigation of IR on Turkish texts using a large-scale test collection. If we revisit our hypotheses stated at the beginning of the article, we can list our findings as follows. We show that within the context of Turkish IR and the retrieval model(s) we used in the experiments,

- a stopword list has no influence on system effectiveness;

- a simple word truncation approach, a word truncation approach that uses corpus statistics, and an elaborate lemmatizer-based stemmer provide similar performances in terms of effectiveness;

- longer queries improve effectiveness; however, this increase is not linearly proportional to the query lengths; and

- longer documents provide higher effectiveness.

Our study conclusively shows that stemming is essential in the implementation of Turkish search engines. With the best performing matching function $M F 8$, the stemming options F5 and LV provide, 33 and 38\%, respectively, higher performance than that of no stemming.

There are several practical implications of our findings, and they are all good news for system developers. No negative impact of not using a stopword list during indexing (with the $t f . i d f$ model we used in the experiments) has possible desirable consequences since users may intentionally submit queries with such common words (Witten et al., 1999). The use of truncated words in indexing rather than the results of a sophisticated stemmer simplifies the implementation of search engines and improves the system effectiveness with respect to no stemming. Better effectiveness with longer queries is a desirable characteristic since it matches the search engine users' expectations.

In the experiments, the matching function $M F 8$ gives a significantly better retrieval performance. Interestingly, $M F 8$ is especially suitable for real-life dynamic collections since in this measure the idf component can easily be reflected to term weighting during query processing. The Milliyet test collection for Turkish, which will be shared with other researchers, is one of the main contributions of this study.

Our work can be enhanced in several ways. The fixed prefix stemming approaches may trim too much (i.e., they may overstem), and the meaning of the stemmed word can be lost. For example, the Turkish word "sinema" (i.e., cinema), which is borrowed from English, becomes "sine" with the F4 stemmer. During searching, this stem may return documents related to "sinek" (i.e., fly, the insect) since they share the same so-called stem "sine" (This is an anecdotal example that we observed during the experiments.) The other extreme, understemming with long prefix values, has its own problems (Frakes \& Baeza-Yates, 1992). The SV and LV stemmers may do a better job in similar situations, but they are imperfect as well. It could be possible to find several problematic cases for any stemmer in any language. In reallife IR applications, some problems introduced by stemming can be resolved before displaying the retrieved documents to the users. For example, in Web applications, this can be done during sineppet generation. Furthermore, the stemming process can be improved to handle compound words. Implementation of some other retrieval approaches [e.g., OKAPI (BM25)], language modeling (Zobel \& Moffat, 2006), mutual information model (Turney, 2002), n-gram-based retrieval (McNamee \& Mayfield, 2004), and cluster-based retrieval (Altingovde, Ozcan, Ocalan, Can, \& Ulusoy, 2007; Can et al., 2004; Can \& Ozkarahan, 1990), all within the context of Turkish IR, are some future research possibilities.

\section{Acknowledgments}

We thank our colleagues, friends, and students for their queries. We thank Sengor Altingovde and the anonymous referees for their valuable and constructive comments. This work is partially supported by the Scientific and Technical Research Council of Turkey (TÜBITAK) under Grant 106E014. Any opinions, findings, and conclusions or recommendations expressed in this article belong to the authors and do not necessarily reflect those of the sponsor.

\section{References}

Ahlgren, P., \& Kekalainen, J. (2007). Indexing strategies for Swedish full text retrieval under different user scenarios. Information Processing and Management, 43(1), 81-102.

Altingovde, I.S., Ozcan, R., Ocalan, H.C., Can, F., \& Ulusoy, O. (2007). Large-scale cluster-based retrieval experiments on Turkish texts [poster]. In Proceedings of the 30th annual International ACM SIGIR Conference on Research and Development in Information Retrieval (ACM SIGIR '07) (pp. 891-892). Amsterdam: ACM.

Altintas, K., \& Can, F. (2002) Stemming for Turkish: A comparative evaluation. In Proceedings of the 11th Turkish Symposium on Artificial Intelligence and Neural Networks (TAINN 2002) (pp. 181-188) İstanbul: İstanbul University Press.

Anderson, S., \& Cavanagh, J. (2006). Report on the top 200 corporations. December 2000. Retrieved October 9, 2006, from http://www.corporations.org/system/top100.html

Asian, J., Williams, H.E., \& Tahaghoghi, S.M.M. (2004). A testbed for Indonesian text retrieval. In Proceedings of the 9th Australasian Document Computing Symposium (ADCS 2004) (pp. 55-58). Australia: University of Melbourne.

Bitirim, Y., Tonta, Y., \& Sever, H. (2002). Information retrieval effectiveness of Turkish search engines. Lecture Notes in Computer Science, 2457, 93-103.

Blair, D.C. (2002). The challenge of document retrieval: Part I. Major issues and a framework based on search exhaustivity, determinacy of representation and document collection size. Information Processing and Management, 38(2), 273-291.

Blair, D.C., \& Maron, M.E. (1985). An evaluation of retrieval effectiveness for a full-text document-retrieval system. Communications of the ACM, 28(3), 289-299. 
Braschler, M., \& Peters, C. (2004). Cross-language evaluation forum: Objectives, results, achievements. Information Retrieval, 7, 7-31.

Braschler, M., \& Ripplinger, B. (2004). How effective is stemming and decompounding for German text retrieval? Information Retrieval, 7, 291-316.

Buckley, C., \& Voorhees, E.M. (2004). Retrieval evaluation with incomplete information. In Proceedings of the 27th International Conference on Research and Development in Information Retrieval (ACM SIGIR '04) (pp. 25-32). Sheffield, UK: ACM.

Cambazoglu, B.B., \& Aykanat, C. (2006). Performance of query processing implementations in ranking-based text retrieval systems using inverted indices. Information Processing and Management, 42(4), 875-898.

Can, F. (2006). Turkish information retrieval: Past changes future. Lecture Notes in Computer Science, 4243, 13-22.

Can, F., Altingovde, I.S., \& Demir, E. (2004). Efficiency and effectiveness of query processing in cluster-based retrieval. Information Systems, 29(8), 697-717.

Can, F., Kocberber, S., Balcik, E., Kaynak, C., Ocalan, H.C., \& Vursavas, O.M. (2006). First large-scale information retrieval experiments on Turkish texts [Poster]. In Proceedings of the 29th International ACM SIGIR Conference on Research and Development in Information Retrieval (ACM SIGIR '06) (pp. 627-628). Seattle, WA: ACM.

Can, F., \& Ozkarahan, E.A. (1990). Concepts and effectiveness of the cover coefficient-based clustering methodology for text databases. ACM Transactions on Database Systems, 15(4), 483-517.

Carterette, B., Allan, J., \& Sitaraman, R.K. (2006). Minimal test collections for retrieval evaluation. In Proceedings of the 29th International Conference on Research and Development in Information Retrieval (ACM SIGIR '06) (pp. 268-275). Seattle, WA: ACM.

CLEF. (2007). Cross language evaluation forum. Retrieved June 24, 2007, from http://www.clef-campaign.org/

Ekmekçioğlu, F.C., \& Willett, P. (2000). Effectiveness of stemming for Turkish text retrieval. Program, 34(2), 195-200.

Figuerola, C.G., Gomez, R., Rodriguez, A.F.Z., \& Berrocal, J.L.A. (2006). Stemming in Spanish: A first approach to its impact on information retrieval. In C. Peters (Ed.), Working Notes for the CLEF 2001 Workshop, Darmstadt, Germany. Retrieved September 3, 2006, from http://www.ercim.org/publication/ws-proceedings/CLEF2/figuerola.pdf

Fox, C. (1990). A stop list for general text. SIGIR Forum, 24(1-2), 19-35.

Frakes, W.B., \& Baeza-Yates, R. (1992). Information retrieval: Algorithms and data structures. Englewood Cliffs, NJ: Prentice Hall.

Grimes, J.E., \& Grimes, B. F. (1996). Ethnologue: Language family index to the thirteenth edition of the Ethnologue. Dallas, TX: Summer Institute of Linguistics.

Hafer, M.A., \& Weiss, S.F. (1974). Word segmentation by letter successor varieties. Information Storage and Retrieval, 10, 371-385.

Hakkani-Tür, D.Z. (2000). Statistical language modeling for agglutinative languages. Unpublished doctoral thesis, Bilkent University, Department of Computer Engineering, Ankara, Turkey.

Harman, D. (1991). How effective is suffixing? Journal of the American Society for Information Science, 42(1), 7-15.

Harter, S.P. (1986). Online information retrieval: Concepts, principles and techniques. San Diego: Academic Press.

Hull, D. (1996). Stemming algorithms: A case study for detailed evaluation. Journal of the American Society for Information Science, 47(1), $70-84$.

Jansen, B.J., \& Spink, A. (2006). How are we searching the World Wide Web? A comparison of nine search engine transaction logs. Information Processing and Management, 42(1), 248-263.

Kettunen, K., Kunttu, T., \& Jarvelin, K. (2005). To stem or lemmatize a highly inflectional language in a probabilistic IR environment? Journal of Documentation, 61(4), 476-496.

Köksal, A. (1981). Tümüyle özdevimli deneysel bir belge dizinleme ve erişim dizgesi: TÜRDER. In Proceedings of 3. Ulusal Bilişim Kurultayı, 37-44. TBD 3. Ulusal Bilişim Kurultayı, 6-8 Nisan, Ankara, 37-44.

Krovetz, R. (1993). Viewing morphology as an inference process. In Proceedings of the 16th International Conference on Research and Development in Information Retrieval (ACM SIGIR'93) (pp. 191-202). Pittsburgh, PA: ACM.

Larkey, L.S., Ballesteros, L., \& Connell, M. (2002). Improving stemming for Arabic information retrieval: Light stemming and co-occurrence analysis. In Proceedings of the 25th International Conference on Research and Development in Information Retrieval (ACM SIGIR' 02) (pp. 275-282). Tampere, Finland: ACM.

Lee, D.L., Chuang, H., \& Seamons, K. (1997). Document ranking and the vector-space model. IEEE Software, 14(2), 67-75.

Lewis, G.L. (1988). Turkish grammar (2nd ed). Oxford, England: Oxford University Press.

Long, X., \& Suel, T. (2003). Optimized query execution in large search engines with global page ordering. In Proceedings of the 29th Very Large Data Bases Conference (VLDB 2004) (pp. 129-140). Berlin: Kaufmann.

McNamee, P., \& Mayfield, J. (2004). Character n-gram tokenization for European language text retrieval. Information Retrieval, 7, 73-97.

NTCIR. (2007). NII test collection for IR systems. Retrieved June 24, 2007 , from http://research.nii.ac.jp/ntcir/

Oflazer, K. (1994). Two-level description of Turkish morphology. Literary and Linguistic Computing, 9(2), 137-148.

Pembe, F.C., \& Say, A.C.C. (2004). A linguistically motivated information retrieval system for Turkish. Lecture Notes in Computer Science, 3280 , $741-750$.

Popovic, M., \& Willett, P. (1992). The effectiveness of stemming for natural-language access to Slovene textual data. Journal of the American Society for Information Science, 43(5), 384-390.

Robertson, S.E. (1981). The methodology of information retrieval experiment. In K. Sparck Jones (Ed.), Information retrieval experiment (pp. 9-31). London: Butterworths.

Salton, G., \& Buckley, C. (1988). Term weighting approaches in automatic text retrieval. Information Processing and Management, 24(5), 513-523.

Sanderson, M., \& Zobel, J. (2005). Information retrieval system evaluation: Effort, sensitivity, and reliability. In Proceedings of the 28th International Conference on Research and Development in Information Retrieval (ACM SIGIR' 05) (pp. 162-169). Salvodor, Brazil: ACM.

Savoy, J. (1999). A stemming procedure and stopword list for general French corpora. Journal of the American Society for Information Science, 50(10), 944-952.

Savoy, J. (2006). Light stemming approaches for the French, Portuguese, German and Hungarian languages. In Proceedings of the 21st annual Symposium on Applied Computing (ACM SAC' 06) (pp. 1031-1035). Dijon, France: ACM.

Semel, T. (2006). The next Yahoo!: Defining the future. Retrieved June 3, 2006, from http://yhoo.client.shareholder.com/downloads/2006Analyst Day.pdf

Sever, H., \& Bitirim, Y. (2003). FindStem: Analysis and evaluation of a Turkish stemming algorithm. Lecture Notes in Computer Science, 2857, 238-251.

Sever, H., \& Tonta, Y. (in press). Truncation of content terms for Turkish. CICLing, Mexico (to appear).

SMART. (2007). SMART FTP Web site. Retrieved July 2, 2007, from ftp://ftp.cs.cornell.edu/pub/smart/

Solak, A., \& Can, F. (1994). Effects of stemming on Turkish text retrieval. In Proceedings of the 9th International Symposium on Computer and Information Sciences (ISCIS '94) (pp. 49-56). Antalya.

Sparck Jones, K. (1981). Retrieval system tests. In K. Sparck Jones (Ed.), Information retrieval experiment (pp. 213-255). London: Butterworths.

Thompson, P., Turtle, H.R., Yang, B., \& Flood, J. (1994). TREC-3 ad hoc retrieval and routing experiments using the WIN system. In Proceedings of the 3rd Text Retrieval Conference, NIST Publication No. 500-226, Gaithersburg (MD). Retrieved July 1, 2007, from trec.nist.gov/pubs /trec3/papers/west.ps.gz

Tordai, A., \& de Rijke (2006). Four stemmers and a funeral: Stemming in Hungarian at CLEF 2005. Lecture Notes in Computer Science, 4022, $179-186$. 
TREC. (2007). Text Retrieval Conference. Retrieved June 24, 2007, from http://trec.nist.gov

Turney, P.D. (2002). Thumbs up or thumbs down? Semantic orientation applied to unsupervised classification of reviews. In Proceedings of the 40th annual meeting of the Association for Computational Linguistics (ACL 2002) (pp. 417-424). Philadelphia.

Voorhees, E. (2005). TREC: Improving information access through evaluation. Bulletin of the American Society for Information Science and Technology, 32(1). Retrieved October 8, 2006, from http://www.asis.org/Bul letin/Oct-05/voorhees.html
Voorhees, E.M., \& Harman, D.K. (2005). TREC experiments and evaluation in information retrieval. Cambridge, MA: MIT Press.

Witten, I.H., Moffat, A., \& Bell, T.C. (1999). Managing gigabytes: Compressing and indexing documents and images (2nd ed.). San Francisco: Kaufmann.

Zobel, J. (1998). How reliable are the results of large-scale information retrieval experiments? In Proceedings of the 21st International Conference on Research and Development in Information Retrieval (ACM SIGIR' 98) (pp. 307-314). Melbourne, Australia: ACM.

Zobel, J., \& Moffat, A. (2006). Inverted files for text search engines. ACM Computing Survey, 38(2), 1-56.

\section{Appendix A}

TABLE A1. Stopword list with 147 words.

\begin{tabular}{|c|c|c|c|c|c|c|c|}
\hline ama & böyle & dolayısıyla & her & ki & olmak & sadece & yaptı̆̆g \\
\hline ancak & böylece & edecek & herhangi & kim & olması & $\operatorname{siz}$ & yaptığını \\
\hline arada & $\mathrm{bu}$ & eden & herkesin & kimse & olmayan & şey & yaptıkları \\
\hline ayrica & buna & ederek & hiç & $\mathrm{m} 1$ & olmaz & şöyle & yerine \\
\hline bana & bundan & edilecek & hiçbir & $\mathrm{mi}$ & olsa & şu & yine \\
\hline baz1 & bunlar & ediliyor & için & $\mathrm{mu}$ & olsun & şunları & yoksa \\
\hline belki & bunları & edilmesi & ile & mü & olup & tarafından & zaten \\
\hline ben & bunların & ediyor & ilgili & nasıl & olur & üzere & \\
\hline beni & bunu & eğer & ise & ne & olursa & var & \\
\hline benim & bunun & etmesi & işte & neden & oluyor & vard 1 & \\
\hline beri & burada & etti & itibaren & nedenle & ona & ve & \\
\hline bile & çok & ettiği & itibariyle & $\mathrm{O}^{*}$ & onlar & veya & \\
\hline bir & çünkü & ettiğini & kadar & olan & onları & ya & \\
\hline birçok & $\mathrm{da}$ & gibi & karşın & olarak & onların & yani & \\
\hline biri & daha & göre & kendi & oldu & onu & yapacak & \\
\hline birkaç & de & halen & kendilerine & olduğu & onun & yapilan & \\
\hline biz & değil & hangi & kendini & olduğunu & öyle & yap1lması & \\
\hline bize & diğger & hatta & kendisi & olduklarını & oysa & yapıyor & \\
\hline bizi & diye & hem & kendisine & olmadı & pek & yapmak & \\
\hline bizim & dolayı & henüz & kendisini & olmadığg 1 & rağmen & yapt1 & \\
\hline
\end{tabular}

*Among letters, only "o" is listed as a word (since it is a meaningful word in Turkish).

TABLE A2. News categories.

\begin{tabular}{clccl}
\hline Category & Category description & No. news & Category & Category description \\
\hline 1 & Accidents & 2 & 7 & Health news \\
2 & Acts of violence or war & 8 & 8 & Legal/criminal cases \\
3 & Art and culture news & 7 & 9 & Miscellaneous news \\
4 & Celebrity and human interest & 2 & 10 & Natural disasters \\
5 & Education news & 5 & 11 & Political and diplomatic news \\
6 & Financial news & 10 & 12 & 5 \\
\end{tabular}

TABLE A3. Query topics.

\begin{tabular}{|c|c|c|c|}
\hline Query & Topic (news category no., no. of relevant news) & Query & Topic (news category no., no. of relevant news) \\
\hline 1 & kuş gribi $(7,18)$ & 13 & Türkiye'de internet kullanımı $(9,220)$ \\
\hline 2 & Kıbris sorunu $(11,115)$ & 14 & Amerika Irak işgal demokrasi petrol $(2,87)$ \\
\hline 3 & üniversiteye giriş sınavı $(5,131)$ & 15 & Türkiye'de futbol şikesi $(12,190)$ \\
\hline 4 & tsunami $(10,101)$ & 16 & Fadıl Akgündüz $(8,26)$ \\
\hline 5 & mavi akım doğalgaz projesi $(6,68)$ & 17 & işsizlik sorunu $(6,216)$ \\
\hline 6 & deprem tedbir önlem $(10,124)$ & 18 & 2005 F1 Türkiye grand prix $(12,36)$ \\
\hline 7 & Türkiye PKK çatışmaları $(2,73)$ & 19 & ekonomik kriz $(6,69)$ \\
\hline 8 & film festivalleri $(3,38)$ & 20 & Nuri Bilge Ceylan $(3,35)$ \\
\hline 9 & bedelli askerlik uygulaması $(6,90)$ & 21 & Türkiye'de meydana gelen depremler $(10,142)$ \\
\hline 10 & stresle başa çıkma yolları $(7,117)$ & 22 & ABD-Irak savaşı $(2,159)$ \\
\hline 11 & şampiyonlar ligi $(12,47)$ & 23 & Hakan Şükür'ün milli takım kadrosuna alınmaması $(12,41)$ \\
\hline 12 & 17 ağustos depremi $(10,161)$ & 24 & Avrupa Birliği, Türkiye ve insan hakları $(11,98)$ \\
\hline
\end{tabular}


TABLE A3. Query topics. (Continued)

\begin{tabular}{|c|c|c|c|}
\hline Query & Topic (news category no., no. of relevant news) & Query & Topic (news category no., no. of relevant news) \\
\hline 25 & turizm $(6,158)$ & 49 & Türkiye'de 2003 yilında turizm $(6,185)$ \\
\hline 26 & Türkiye'deki sokak çocukları $(9,140)$ & 50 & Türkiye'nin nükleer santral çalışmaları $(9,53)$ \\
\hline 27 & Türk filmleri ve sineması $(3,151)$ & 51 & hızlı tren kazası $(1,42)$ \\
\hline 28 & Pakistan depremi $(10,62)$ & 52 & YÖK'ün üniversitelerimiz üzerindeki etkisi $(5,195)$ \\
\hline 29 & sanat ödülleri $(3,85)$ & 53 & İbrahim Tatlıses'in kadınları $(4,64)$ \\
\hline 30 & Avrupa Birliği fonları $(6,75)$ & 54 & parçalanmış aileler $(9,40)$ \\
\hline 31 & futbolda şike $(12,212)$ & 55 & aile içi şiddet $(2,143)$ \\
\hline 32 & milletvekili dokunulmazlığı $(8,217)$ & 56 & Türkiye'de kanser $(7,53)$ \\
\hline 33 & 2001 erkekler Avrupa basketbol şampiyonası $(12,35)$ & 57 & futbol terörü ve holiganizm $(12,200)$ \\
\hline 34 & 2002 dünya kupası $(12,27)$ & 58 & Türkiye'de ikinci el otomobil piyasası $(6,93)$ \\
\hline 35 & bilişim eğitimi ve projeleri $(5,156)$ & 59 & tarihi eser kaçakçılı̆̆ $(8,96)$ \\
\hline 36 & global 1sinma $(9,128)$ & 60 & festival $(3,263)$ \\
\hline 37 & Türkiye' de mortgage $(6,95)$ & 61 & Türkiye'de bayram tatillerinde meydana gelen \\
\hline 38 & ABD Afganistan savaşı $(2,57)$ & & trafik kazaları $(1,93)$ \\
\hline 39 & Yüzüklerin Efendisi-Kralın Dönüşü $(3,41)$ & 62 & öğrenmeyi etkileyen faktörler $(5,123)$ \\
\hline 40 & beyin göçü $(9,59)$ & 63 & kekik otu $(9,64)$ \\
\hline 41 & aile kadın şiddet $(2,74)$ & 64 & telif hakları $(3,51)$ \\
\hline 42 & sporcuların doping yapması $(12,239)$ & 65 & internet ve toplum $(9,201)$ \\
\hline 43 & ozon tabakasındaki delik $(7,47)$ & 66 & tarım hayvancılık sorunları $(6,134)$ \\
\hline 44 & Rusya'da okul baskını $(2,99)$ & 67 & İran'da nükleer enerji $(11,237)$ \\
\hline 45 & İstanbul'da bombalı saldırı $(2,130)$ & 68 & satranç $(9,93)$ \\
\hline 46 & Sakıp Sabancı'nın vefatı $(4,101)$ & 69 & kalıtsal hastalıklar $(7,65)$ \\
\hline 47 & Ecevit Sezer çatışması $(11,47)$ & 70 & hiperaktivite ve dikkat eksikliği $(7,36)$ \\
\hline \multirow[t]{2}{*}{48} & Kıbris Türk üniversiteleri $(5,45)$ & 71 & lenf kanseri $(7,28)$ \\
\hline & & 72 & 28 Şubat süreci $(11,76)$ \\
\hline
\end{tabular}

